\title{
Inspissated Bile Syndrome
}

National Cancer Institute

\section{Source}

National Cancer Institute. Inspissated Bile Syndrome. NCI Thesaurus. Code C98956.

A syndrome characterized by persistent jaundice, hemolytic anemia, and hepatomeg aly in a newborn. It is characterized by the presence of inspissated bile plugs in the bile ducts. 